\title{
Comparison on the Tendency of "Local Complex" in the Novels of Shen Congwen and Kim You Jeong
}

\author{
Liyan Xiao \\ College of Foreign Language, Jishou University, Zhangjiajie, 427000,China \\ liyan9349@163.com
}

\begin{abstract}
Keywords: Shen Congwen, Kim You Jeong, local complex
Abstract.: ShenCongwen and Kim You Jeong are the representatives of local novelists from China and Korea in 30's respectively, whose novels are penetrated through by the strong "local complex". This article analyzes the "local complex" and the writing features reflected in their novels by comparing the both motives, and then get a better understanding of their writing features .
\end{abstract}

\section{Introduction}

Shen Congwen and Kim You Jeong are the representatives of local novelists from China and Korea in 30's respectively. However, there are only two theses compared and contrasted with their works. They are Comparative Study on the Local Novels of Shencong wen's and Kim You Jeong 's(2008), written by Zhongmei, and Comparative Study on the Local Novels of Shencong wen's and Kim You Jeong 's(2013), written by Zhu Siwei. And some other comparisons of both writers are scatteredly collected in Comparative Literature of China and South Korea and Literary Works of South Korea, but which is simple and generally.

Their novels share the general features of local ones, but different from those of the Enlightenments. Instead of historical events happened in 30's, their works focuses on the local farmers living in the remote villages which the two writers was familiar with. Their works are penetrated through by the strong " local complex", meanwhile show the sympathy to rural vulnerable groups and express the regret of the farmers' helpless, then reflect the rural social reality and the villagers' spirit condition of China and South Korea in 30's.

\section{The writers' Local Complex and Their Personal Conditions}

In the course of modernization, the advanced science, technology, and culture made their way into China and South Korea from the west so that the two country's society were transformed from traditional agriculture civilization to modernization one, which pushed the appearance of unprecedented culture opening, culture integration, and culture transformation. Under this background, intellectuals embraced a more extensive stage and a wider range of choice and pursuit. Some intellectuals, born in countryside and then experienced the city life, were inevitably shaped and polished by city foreign culture. Shencong wen and Kim You Jeong were two of them.

Shen cong wen was born in a military family in 1902, living Fenghuang county of Xiangxi( west of Hunan), deserted but with picturesque scenery. His family enjoyed a rich life in his childhood, but it didn't last long and gradually faded away result from his father's justice of helping others materially and spiritually. When he graduated from primary school at his 15 , he dropt out to join military. During his time in army, he penetrated the might and force of Xiang( Hunan province) soldiers, and saw though the darkness of various persecution and slaughter. Confronting the ruthless and ignorance of society and life around him, he then mingled "ruthless" and "ignorance" into his works without any possible of showing off seeking novelty. On the contrary, they shaped into a character of pursuing wonderful life and kind virtue. Afterwards, he got in touch with May Fourth New-vernacular Literature, which gave him some vision of new life. Therefore, he got to Beijing alone to attend school, but failed. Finally, he had no choice but to practice writing. At that time, life was hard for him. He once cherished rich 
illusions and expectation for city life, but, truly, he experienced closed doors one after another and was exposed to human indifference and ethical fading. Under the heavy load of city life, with some working experiences of paperwork in army, Shencong wen had to make a living on writing. The bad time spent in city drove his endless missing for rural life. As a result, he put his mind into the memory of his childhood and the ideal life in Xiangxi wholeheartedly, and expressed his contempt and sneering to people of city and the ways of their treating things with particular brushstrokes.

Kim You Jeong was born in a landlord family, coming from Chunchuan County of Kangwondo in South Korea, in 1908. The same as Shencong wen's family, she also lived a very rich life in her childhood. Her misfortune began with the passing away of her parents at her 7 and 9. What's worse, her brother, Kim You Jeong, spent all his time being pampered with excessive extravagance so that their family financial circumstances were bad to worse. When she was in high school, she met a person called Anhuai nan, which made her generate strong interest in literature creation.

In 1929, she was admitted by Yanxi College, but ended up with quitting school because of financial problem and her health condition. Then, she had been lived with her second elder sister, Kim You heng. Because of her body discomfort, study not going well, the poverty-stricken life in city, and discording with her elder brother, she gradually hated the people of city unwittingly.

In 1930, she came back to her hometown to look for the place of comforting her heart and soul. She set up a night school, organized farmer union, and devoted herself into the anti-illiteracy movement. Then she caught tuberculosis result from the failure of gold-mining investment and her indulgent lifestyle. The experiences of that time and understanding to her hometown became the main materials of her after novel creating. Being born and grew up in countryside, and running school in her hometown showed her deep love to her birthplace, so, naturally, she paid much attention to the rural problem and villagers' miserable situation. Then, she lived with her sister again for the worsening of her health condition, thus starting to create novels specially to support the spending of her and her sister's family.

As above, Shencong wen and Kim You Jeong, both born in the declining landlord family, had to make a living on literature creation owing to family's fading and the heavy pressure of life. Bearing the life experience of countryside and city, they were the foreigners of city culture. The unhappy life in city pushed them getting rid of the city upper-level intellectuals at their will to seek for a completely different literature world. The belonging of their soul should be the land of bringing them up. And the hard life in city strengthened their local conscious and made them miss and look forward to their hometown from their bottom of the heart, thus very sympathizing the rural vulnerable groups. So such feeling of missing and sympathy were shattered in their local novels.

\section{“ Local Complex" Reflected in Their Works}

From the huge contrast of culture and literature between urban and rural areas, Shencong wen and Kim You Jeong sensed the awakening of as a " country folk". Countryside, carrying the childhood memory that can be never erased, left them with unforgettable land complex, which made them bear strong sense of crisis.

For dream, Shencong wen came to Beijing, but he wasn't paid back with the same welcomes from Beijing. He cast his eye sight to countryside when extremely disappointed with cities. His desperation to urban civilization brought him back to his hometown, Xiangxi, mentally. He could feel the real state of local culture, haunting in his mind in such showy and luxurious city. He struggled in the conflict between city and local land. He called himself as "country folk".

And Kim You Jeong shared the same experience with Shencong wen. she showed such a conscious version of South Korea countryside under Japan's colonial rule. She knew well about countryside, she loved it, and she sympathized people's miserable life. She began to miss her hometown, Chunchuan, when extremely tired with the unhappy city life. And Chunchuan was the only place to have her heart and soul comforted. 
Shencong wen and Kim You Jeong melted such unforgettable local complex into their local works. They cast the flash of love and kind to native soil with strong idealism, so it helped to shape an ideal countryside described in their works. They didn't tell the tragedy of the countryside, even though there were full of miserable atmosphere in their hometown. On the contrary, by recalling their memory of local land, they depicted the beautiful scenery, ignorant but simple villagers, and, of course, the romantic local love was also included. They could be much found in The Border Town, Xiaoxiao, written by Shencong wen, and Camellia, Mountain Village, written by Kim You Jeong. Such unforgettable local complex provided a homeland for them to comfort their soul mentally. Through painting the beautiful native land, they well expressed their missing to the pass land and longing for its bright future.

\section{The Features of "Local Complex" and Typical Dialect}

The writing techniques of the two writers were very special and unfolded the typical features of local novels. To be worth raising was the applying of dialect and proverb or old saying, which really not only added the realism of works, but also made you feel immersive, thus significantly tasting the people and events of the countryside. Overlooking the whole picture of their local literature, it's easy to find that dialect and proverb were the main form to carry their local literature. They could be found in people's conversation and such local accent haunted in their whole works and mingled with the keynote and lines.

The local language that is Excessive magnificence washed and fabulous appeared in the works of Shencong wen reproduced an ideal world, belonging to a " country folk", that wasn't spoiled entirely by modern civilization. Xiangxi dialect were shattered here and there in his novels, such as "Dalao"( first son), "Erlao"( second son), used to call their children. And others like "guolu" ( luguo in mandarin) ( pass by), "yanhuai" ( yansi in mandarin) ( be drowned), "baifayingdian" ( mantoubaifa in mandarin) (white haired), "koufeng" ( kouxin in mandarin) ( oral message), " xiapa" ( haipa in mandarin ) ( be afraid of), "zhangnian" (changgong in mandarin) (longterm hired hand), "denglongzi" ( yanjing in mandarin) ( eye), " huagouda" ( huagou is a name, da is used to call elder brother), "jianhexian" ( shidaosui in mandarin) ( pick up grain in fields) ect., were all the dialect from Xiangxi. Shencong wen also preferred to use metaphors that villagers usually said to express their thinking. For instance, "chuche" meant paying court to a women by competing singing, and "tiaoma" was said to be a matchmaker, which were all the vivid metaphor from Chinese chess. Xiangxi songs also played an important role in his novels. For example, the song of carrying promise out to welcome God, from Wizards December, was hummed by Cuicui, the heroin of The Border Town, when in boat. But what's more, the vivid Xiangxi dialect acted as a kind of potential language background, thus becoming an organic part of the text.

Because of being in remote areas and secluded from the world, there were still some vestiges of ancient oral Chinese and classical Chinese kept in Xiangxi dialect. His novel language appeared to be very simple, natural, and refined. He also injected the rhyme of poem to realize the image stream between object and I, being permeated with classical atmosphere. Some people would say it's difficult to catch the shadow of Xiangxi dialect besides some place names as "Chadong", but they unfolded a simple, natural, and beautiful life picture that peculiar to Xiangxi.

As well, in Kim You Jeong's works, against the countryside background, dialect could be found everywhere. It's not only because of her bearing and growing up in countryside, but also her hometown,Chunchuan, was a destination physically and mentally. Every word spoken in Chunchuan was deep-rooted for her, so in her local novels, the words different from the standard Korea can be seen everywhere, such as mountain, wood door, happy), waist of trousers, intelligent and capable, do nothing, wasteland), ear, a girl to be a hostess to drink with others ect., were all peculiar to her homeland, Chunchuan. 
Both Shencong wen and Kim You Jeong kept special feeling to their own native land. The strong tendency of " local complex" diffused in their works. Praising, mourning, disclosing, or criticizing all presented the writer's struggling and fighting between the ideal and the reality.

\section{Acknowledgement}

This article is supported by Project of Social Science of Hunan Provincial Fund under grant 13WLH48 and 15WLH39.

\section{References:}

[1] Qianli qun, Modern Chinese Literature 30 Years [M], Peking University Press, 1998, P212

[2] Shencong wen, An Anthology of Writing, Anthology of Shencong wen [M], the fifth volume, Sichun People's Press, 1983, P229

[3] Kim You Jeong, Lover Gone, The Complete Works of Jinyu zhen [M], the Institute of Jinyu zhen Commemoration, 1988, P244

[4] Shencong wen, The Border Town, Collection of Shencong wen [M], the sixth volume, Huacheng Publishing House, 1983, P73

[5] Dongzheng yu, Shencong wen And Xiangxi dialect [J], Journal of Jishou University, the 27th volume, fourth stage, 2006 